\title{
Low Back Pain At Work: Knowledge and Attitude of Sectional Heads At the University College Hospital, Ibadan
}

\author{
Odole A.C., Adegoke B.O.A., Akinpelu A.O., Okafor A.C. \\ Department of Physiotherapy, College of Medicine, University of Ibadan \\ Correspondence \\ Dr A.C. Odole. E-mail: adesola_odole@yahoo.com
}

\section{SUMMARY}

The purpose of this study was to find out the knowledge and attitude of sectional heads towards managing low back pain (LBP) at work at the University College Hospital, Ibadan. It was also aimed at identifying the difficulties encountered and the organizational needs required in the management of LBP at work.

Twenty-nine sectional(16 male and 13 female) heads at the University Teaching Hospital participated in this cross-sectional survey. The participants completed a self-administered questionnaire, adapted from the Management of LBP in the Workplace Questionnaire. Data was analysed using descriptive statistics of mean, standard deviation, frequency, percentages and inferential statistics of Chi square. Level of significance was set at 0.05 .

Twenty-six $(89.7 \%)$ of the participants reported no difficulty in managing staff members with low back pain. Seventeen (58.6\% ) participants had poor knowledge, while $37.9 \%$ had fair to good knowledge of managing LBP at work. Twenty-two participants had a positive attitude tow ards managing staff members with low back pain. There was no significant association $(\mathrm{p}=0.307)$ between respondents' knowledge and attitude towards managing workers with LBP. Organizing workshops for workers was the most frequently reported organizational support required for the management of LBP.

Sectional heads at the University College Hospital, Ibadan have poor knowledge but a positive attitude towards managing workers with LBP.

\section{INTRODUCTION}

Low Back Pain (LBP) represents the leading musculoskeletal cause of disability and is the most frequently reported condition for which people receive outpatient physiotherapy (Jette et al, 1994). It has been referred to as a $20^{\text {th }}$ century enigma which continues to cause disability and distress in a large proportion of the adult population (Waddel, 1998). LBP may not be a life threatening condition but it constitutes a major health problem in the world (Deyo and Phillips, 1996). It is usually accompanied by the painful limitation of movement, often influenced by physical activities and posture, and may be associated with referred pain (Kovac et al, 2006).

The incidence of low back pain has continued to increase in modern societies such as the UK, USA and Canada (Cole et al, 2003). Its prevalence rates have been reported to be $39 \%$ in the UK (Hilman et al, 1998) and
$21 \%$ in Hong Kong (Lau et al, 1995). A cross-sectional study in a rural hospital in south-western Nigeria revealed that the prevalence of LBP among health workers was $46 \%$, with the highest prevalence of LBP $(69 \%)$ recorded among nursing staff, followed by secretaries/administrative staff $(55 \%)$ and cleaners/aides(47\%) (Omokhodion et al, 2000).

Various studies have reported the prevalence of LBP among health workers (Omokhodion et al, 2000; Sanya and Ogwumike, 2005), with nurses and physiotherapists more at risk as a result of repetitive lifting, prolonged standing and sitting (Hollingdale and Warin, 1997). Jobs that require the workers to sit or stand for a long period of time are at risk for LBP and similarly, persons who are required to do heavy or frequent lifting are also at risk of LBP (Anderson, 1999) and this is one of the major causes of loss of working hours and days among the hospital workers. 
Many studies have explored LBP in relation to specific work sectors and found a high level of LBP and related disability among health service workers (Rossi et al, 1999).

Low Back Pain (LBP) being the most common musculoskeletal problem in the work place (Omokhodion and Sanya, 2003), is a major cause of work- related disability (Cunningham et al, 2008), which is associated with major costs in terms of health resource usage, worker disability and absenteeism (Maniadaki and Gray, 2000). LBP has been established as one of the most common reasons for sick leave in the western world (Reiso et al, 2003).

Emphasis has been placed on the important role of supervisors in reducing work-related disability among hospital workers (Carter and Birrell, 2000). Sectional heads in this study were those heading different sections or units and departments in the University Teaching Hospital, Ibadan. Advice by health professionals to continue to work or Return To Work (RTW) despite LBP is unlikely to be successful in the absence of both organizational and hospital manager's support in the workplace (Cunningham et al, 2008). McLellan et al (2001) highlighted the critical role of supervisors in occupational health and reported that proactive disability management practices such as organizing training sessions among employers have been associated with reduced frequency and duration of disability. Sectional heads as supervisors are most familiar with the requirements of the job and are the first to communicate with the workers about their RTW order and usually have the authority to implement adjustments in working conditions.

Hospital managers come into contact with their employees daily and are in a position to act as change and rehabilitation agents (Kushnir and Luria, 2002). Supervisory behaviour is regarded as an important determinant of RTW (Linton, 1991; Nieuwenhuijsen et al, 2004). Positive supervisory behaviour has been found to be associated with fewer work days lost and better job accommodation in employees who had successfully returned to work after LBP (Habeck et al, 1998).

Despite an increasing emphasis on the role of employers in rehabilitation, little scientific knowledge has been acquired on this subject (Nordqvist et al, 2003). Many studies have been conducted in relation to the hospital manager's role in RTW of individuals after myocardial infarction or coronary bypass surgery (Kushnir and Luria, 2002). Published studies on sectional heads' role as supervisors in the management of LBP appear to be few, and research regarding the knowledge and attitude of hospital manager's role in managing the worker with LBP is lacking in Nigeria.

\section{MATERIALS AND METHODS}

This cross-sectional survey was approved by the University of Ibadan and University College Hospital's Research Ethics Committee. The protocol was explained to each participant and his/her informed consent was obtained. The participants were all consenting workers in the University College Hospital (UCH), Ibadan. They included heads of departments, assistant and deputy directors of nursing, assistant and deputy directors of pharmacy, assistant and deputy directors of physiotherapy and medical doctors. The instrument for data collection was an adapted questionnaire from the Management of Low Back Pain in the Workplace Questionnaire (MLBPWQ) (Cunningham et al, 2008). In the adaptation of the MLBPWQ, 4 items that were not applicable to the $\mathrm{UCH}$ were deleted while 6 items were modified by replacing the name of the hospital where the study by Cunningham et al (2008) was carried out with the UCH. The adapted version of the MLBPWQ (appendix 1) has 39 items and is divided into 4 sections. Section A has seven 7 items on sociodemographic information of participants; Section B has 8 items on participants' knowledge on LBP management at work; Section C has 20 items on participants' attitude towards LBP management at work; and Section D has 4 open-ended questions with an item each on participants' difficulty in managing LBP at work, factors that might hinder return to work of staff member with low back pain, and support towards management of LBP at work. The respondentswere asked to indicate their level of agreement with items on section $\mathrm{C}$ on a Likert scale, where $1=$ completely disagree (score of -2 ), $2=$ disagree (score of -1 ), $3=$ neutral (score of 0$), 4=$ agree $($ score of +1$)$ and $5=$ completely agree $($ score of +2$)$. The statements were a mix of 11 true (positive attitudinal responses with a maximum score of +40 ) and 9 false statements (negative attitudinal responses with a maximum score of -40) to avoid respondents becoming biased towards one end of the scale. Items 20, 21, 22, 23, 28, 29, 30, 35, 36, 38, 39 were true statements denoting a positive attitude when respondents agree or completely agree, and vice-versa. The remaining 9 items were false statements denoting a positive attitude when respondents agree or completely agree, and viceversa. The questionnaire was assessed for content and face validity at an undergraduate physiotherapy seminar. It was also reviewed by four lecturers who are knowledgeable in questionnaire design and development to ensure that it has good content and face validity, with clear and unambiguous 
Odole, Adegoke, Akinpelu, Okafor

questions. Copies of the questionnaire were distributed to the participants by hand and the completed copies were collected through the same means. One of the authors waited to collect completed copies where possible and returned to collect them after a week when immediate collection was not possible.

\section{Data analysis}

Data were summarized using frequency, percentage, median, mean standard deviation. Participants' knowledge was graded based on their score in the knowledge section of the questionnaire as follows: Poor: $\leq 25$, Fair: 26-50, Good: 51-75, Excellent: 76-100. Also, participants' attitude was graded based on their scores in the attitude section of the questionnaire as follows: Negative: $-40-0$, Positive: 0 40. Inferential statistics of Chi square test were used to analyse the association between the knowledge and attitude of the clinical consultants and sectional heads towards managing LBP at the workplace. The alpha level was set at 0.05

\section{Results}

Twenty-nine sectional heads comprising 16 males $(55.2 \%)$ and 13 females $(44.8 \%$ ) participated in the study. Their age ranged from 30 to 63 years with a mean of $48.7 \pm 8.83$ years. Fifteen $(51.3 \%)$ of the respondents were within the age range of 30 to 49 and $14(48.7 \%)$ were within the 50 to 63 age range. Twenty-five $(86.2 \%)$ were married, $3(10.3 \%)$ were single, and $1(3.4 \%)$ was widowed. Five (17.2\%) participants were doctors, $4(13.8 \%)$ were physiotherapists, while $3(10.3 \%)$ were pharmacists (table 1$)$.

Over two-thirds $(72.1 \%)$ of the participants had spent 2 to 7 years in their current management post while $27.9 \%$ had spent 10 to 30 years in their current management post. Almost two-thirds $(65.2 \%)$ had 4 to 12 years experience in management while $34.8 \%$ had 13 to 30 years experience in management. Half of the participants $(51.5 \%)$ had 2 to 19 members of staff, $27.4 \%$ had 20 to 40 members of staff and $21.1 \%$ had over 40 members of staff that were being managed for LBP.

Over three-quarters of the participants responded that physiotherapists, personnel department and occupational health department were responsible for ensuring manual handling training. Sixteen $(55.2 \%)$ participants responded that a staff member with LBP should report to the staff clinic, $6(20.9 \%)$ responded that the staff member should take an analgesic, $1(3.4 \%)$ responded that the staff member should report to the physiotherapy clinic, while 4 $(13.8 \%)$ did not know the steps to take in case a staff member has LBP while at work.
Table 1. Socio-demographic characteristics of participants

\begin{tabular}{l|c|c}
\hline Characteristic & Frequency & Percentage \\
\hline Sex & 16 & 55.2 \\
Male & 13 & 44.8 \\
Female & & \\
\hline Marital Status & 25 & 86.2 \\
Single & 3 & 10.3 \\
Married & 1 & 3.4 \\
Divorced & & \\
\hline Occupation & 5 & 17.2 \\
Doctors & 4 & 13.8 \\
Physiotherapist & 1 & 3.4 \\
Nurses & 1 & 3.4 \\
Engineer & 6 & 20.7 \\
Dentist & 3 & 10.3 \\
Pharmacist & & \\
Medical social & 2 & 6.9 \\
worker & 1 & 3.4 \\
Medical lab scientist & 2 & 6.9 \\
Civil servants & 1 & 3.4 \\
Surgeon & 2 & 6.9 \\
Microbiologist & & 3.4 \\
Health records & 1 & \\
officer & & \\
\hline
\end{tabular}

Ten $(34.5 \%)$ participants responded that they would communicate with the physiotherapist only, $3(10.3 \%)$ responded that they would communicate with the occupational therapist, $5(17.2 \%)$ responded that they would communicate with the staff member, $2(6.9 \%)$ responded that they would communicate with the head of department and personnel department, 1 (3.4\%) each responded that they would communicate with the personnel department, orthopaedic surgeon, head of department and physiotherapist, and personnel and staff member, respectively, while $5(17.2 \%)$ said that they do not know whom to communicate with in the case of a staff member taking sick leave because of LBP. Seventeen $(58.7 \%)$ had poor knowledge, $9(31 \%)$ had fair knowledge, $2(6.9 \%)$ had good knowledge, and $1(3.4 \%)$ had excellent knowledge towards managing staff members with low back pain (table 2).

The attitude score ranged from -40 to 40 . The participants with scores of -40 to 0 were graded as having a negative attitude while those with scores of 0 to 40 were graded as having a positive attitude. Seven $(24.1 \%)$ participants had a negative attitude towards managing staff members with low back pain while $22(75.9 \%)$ had a positive attitude towards managing staff members with low back pain. The most frequently reported organizational support $(34.5 \%)$ required in the management of LBP at work was organizing workshops for the sectional heads. 
Three participants responded that free physiotherapy facilities should be offered to the staff with low back pain, 3 also responded that lectures on managing staff members with low back pain should be given by physiotherapists and 5 did not know the type of organizational support they needed in managing staff members with low back pain (table 3).

Table 2. Participants' responses on provision of organizational support by UCH

\begin{tabular}{l|c|c}
\hline Responses & $\mathrm{N}$ & $\%$ \\
\hline 1. Equipping physiotherapy adequately & 1 & 3.4 \\
\hline 2. Organizing workshops & 10 & 34.5 \\
\hline 3. Offer free physiotherapy facilities & 3 & 10.3 \\
\hline $\begin{array}{l}\text { 4. Lectures given on PT recommendations on } \\
\text { managing staff members with LBP }\end{array}$ & 3 & 10.3 \\
\hline $\begin{array}{l}\text { 5. Rely on PT recommendations on managing } \\
\text { staff members with LBP }\end{array}$ & 2 & 6.9 \\
\hline 6. Pre-placement back care education & 3 & 10.3 \\
\hline 7. Proper job evaluation before RTW & 1 & 3.4 \\
\hline 8. Providing first aid boxes in all offices & 1 & 3.4 \\
\hline 9. Don't know & 5 & 17.2 \\
\hline
\end{tabular}

Key: PT: Physiotherapist, LBP: Low back pain; RTW: Return to work

Table 3. Participants' overall knowledge of managing low back pain

\begin{tabular}{l|c|c}
\hline $\begin{array}{l}\text { Respondents' } \\
\text { knowledge }\end{array}$ & $\mathrm{N}$ & $\%$ \\
\hline Poor & 17 & 58.6 \\
\hline Fair & 9 & 31.0 \\
\hline Good & 2 & 6.9 \\
\hline Excellent & 1 & 3.4 \\
\hline
\end{tabular}

Twenty-six participants $(89.7 \%)$ did not have any difficulty in managing the staff members with low back pain, while 3 $(10.3 \%)$ had difficulty in managing staff members with low back pain. There was no significant association $\left(x^{2}=2.36\right.$, $\mathrm{p}=0.307$ ) between respondents' knowledge about low back pain and attitude towards management of low back pain (table 4).

Table 4. Association between participants' knowledge and attitude

\begin{tabular}{|c|c|c|c|c|c|}
\hline \multirow{2}{*}{$\begin{array}{l}\text { Respondents' } \\
\text { knowledge }\end{array}$} & \multicolumn{3}{|c|}{ Respondents' attitude } & \multirow[b]{2}{*}{$x^{2}$} & \multirow[b]{2}{*}{$\mathrm{P}$} \\
\hline & Negative & Positive & Total & & \\
\hline Poor & $3(10.3 \%)$ & $14(48.3 \%)$ & $17(56.8 \%)$ & \multirow{3}{*}{2.36} & \multirow{3}{*}{0.307} \\
\hline Fair & $0(0 \%)$ & $9(31.0 \%)$ & $9(31.0 \%)$ & & \\
\hline Good & $0(0 \%)$ & $3(10.3 \%)$ & $3(10.3 \%)$ & & \\
\hline
\end{tabular}

\section{DISCUSSION}

The results of this study suggest that sectional heads in the University College Hospital had a poor knowledge of, but a positive attitude towards managing staff members with low back pain at the workplace. This could be attributed to the fact that many of the participants in this study probably did not know their roles as heads/supervisors in the management of this disabling condition. A few studies from different countries all over the world (Cunningham et al, 2008; Williams et al, 2007; Williams and Westermorland, 2002; McLellan et al, 2001; Shrey and Hursh, 1999) have been published on the role of managers (sectional heads/supervisors) in managing LBP in the work place, but none has been published in Nigeria.

The respondents were aware of the difficulties that physicalworkload may present for the worker with LBP but felt they needed greater organizational support in order to provide modified duties for their staff. This study's result may not be extrapolated to other groups of workers or other work settings since the study focussed on health service workers only and in one specific work setting (tertiary health institution). Also, the lack of previous research in this area makes this study unique while making comparison with similar studies in Nigeria impossible.

This study appears to be the first to explore the knowledge and attitude of sectional heads and clinical consultants on the management of LBP in the workplace in Nigeria. A similar study was carried out at the Irish University Hospital, Ireland by Cunningham et al (2008), which was one of the first studies that explored the role of linemanagers in the management of LBP in the workplace. This situation limits the extent to which findings from this study can be compared to similar/related studies. Only 3 $(1.3 \%)$ of the participants in this study had difficulty in managing staff members with LBP. This is in contradiction to the findings in the study by Cunningham et al (2008) where as many as $30(53.0 \%)$ of the participants had difficulty in managing staff members with LBP. Also, participants in this study had poor knowledge of the management of LBP in the work place, while the results of the study by Cunningham et al (2008) revealed that the participants had good knowledge. This could probably be due to the emphasis placed on the important roles of hospital managers in the reduction of work-related disability among workers as contained in the UK's occupational health guidelines for the management of LBP in the workplace (Waddel and Burton, 2000). Such guidelines appear to be non-existent in Nigeria. However, in both studies, the participants' attitude to managing LBP in the work place was positive. The Whitehall II study 
reported by Ferrie (2004) emphasized the importance of manager and co-workers' support in reducing sick leave. Sectional heads and clinical consultants surveyed in this study appeared to be focussing on organizational support and free physiotherapy treatment, though research has shown that workers believe their supervisors have significant roles to play in the RTW process and that manager support, high job satisfaction and good industrial relations are regarded as the most importantorganizational characteristics associated with low back disability and backrelated sickness absence from work (Carter and Birrell, 2000). According to the Safety, Health and Welfare at Work (Ireland) Act (2005), all managers were required to give their staff manual handling training. Only $41 \%(n=$ 24) of managerssurveyed by Cunningham et al (2008) were aware that the responsibility of ensuring staff received such training lays solely with them. This poses a challenge to the legislative body in Nigeria where such legislation that pertains to the safety, health and welfare of workers appears to be non-existent. The sectional heads' knowledge on the evidence regarding their role in LBP management needs to be improved.

\section{References}

Andersson, G. 1999. The epidemiology of spinal disorders. In Frymoyer J.W (ed). The Adult Spine: Principles and Practice. Philadelphia, Lippincott-Raven; 93-141.

Carter, J.T. and Birrell L.N. 2000. Occupational Health Guidelines for the Management of Low Back Pain at Work-Principal Recommendations London: Faculty of Occupational Medicine.

Cole A.J., Heithoff K.B., and Herzog, R.J. 2003. The lumbar spine: Imaging options. In Cole A.J., Herring S.A. (eds), The Low Back Pain Handbook: A guide for the practising clinician $2^{\text {nd }}$ edition. Philadelphia: Hanley and Belfus, pp. 219-262.

Cunningham C., Doody C. and Blake C. 2008. Managing low back pain: knowledge and attitude of hospital manager. Journal of Occupational Medicine 258:282-288.

Deyo, R. and Phillips W. 1996. Low back pain: A primary care challenge. Spine 21:2826-32.

Ferrie, J.E. 2004. Work, Stress and Health: Whitehall II Study London: University College London Publications 15: 43-45.

Habeck, R.V., Hunt H.A. and VanTol B.1998. Workplace factors associated with preventing and managing work disability. Rehabilitation Counseling Bulletin 42:98-143.

Hanley, E.N. and David S.M. 1999. Lumbar arthrodesis for the treatment of back pain. Journal of Bone and Joint Surgery 81:716-730.

Hillman, M. Vartianen E., Heliovaara M. and Puska P. 1998. Trends of back pain in relation to socioeconomic status and behavioral risk factors. American Journal of Epidemiology 148: 671-682.
Hollingdale, R. and Warin J. 1997. Back pain in nursing and associated factors: A study. Nursing Standard 11: 35-38.

Jette, A.M., Smith K., Haley S. and Davis K.D. 1994. Physical therapy episode of care for patients with low back pain. Physical Therapy 74; 101- 115.

Kovac F.M., Muriel A., Medina J.M., Abraira V., Sanchez M.D.C., Jauregi J.O. and the Spanish Back Pain Research Network. 2006. Psychometric characteristics of the Spanish version of the FAB questionnaire. Spine 31: 104-110.

Kushnir, T. and Luria O. 2002. Supervisors' attitudes toward return to work after myocardial infarction or coronary artery bypass graft. Occupational Environment Medicine 44:331-327.

Lau, E.M., Egger P., Coggon D., Copper C., Valenti I. and O'Connell D. 1995. Low back pain in Hong Kong: Prevalence and characteristics compared with Britain. Journal of Epidemiology and Community Health 49:492-494.

Linton, S.J. 1991. Manager's role in employees' successful return to work following back injury. Work Stress 5:189-195.

Maniadakis, N. and A. Gray. 2000. The economic burden of back pain in the UK. Pain 84:95-103.

McLellan, R.K., G. Pransky and W.S. Shaw. 2001. Disability management training for supervisors: A pilot intervention program. Journal of Occupational Rehabilitation 11:33-41.

Nieuwenhuijsen, K., J.H.A.M. Verbeek, A.G.E.M. de Boer, R.W.B. Blonk and F.J.H. van Dijk. 2004. Supervisory behaviour as a predictor of return to work in employees absent from work due to mental health problems. Occupational Environmental Medicine 61:817-823.

Nordqvist C., Holmqvist C., Alexanderson K. 2003. Views of lay persons on the role employers play in return to work when sick listed. Journal of Occupational Rehabilitation 13: 11-20.

Omokhodion, F.O. and Sanya A.O. 2003. Risk factors for low back pain in the office workers. Journal of Occupational Medicine 53: 287-289.

Omokhodion, F, Umar U. and Ogunnowo B. 2000. Prevalence of low back pain among staff in a rural population hospital in Nigeria. Journal of Occupational Medicine 50:107-110.

Reiso, H., Nygard J.F., Jorgensen G.S., Holanger R., Soldal D. and Bruusgaard D. 2003. Back to work: Predictors of return to work among patients with back disorders certified as sick. Spine 28: 1468-1473.

Rossi. A., Marinon G., Barbieri L. et al. 1999. Backache from exertion in health personnel. A case control study of the injury phenomenon in the 10-year period of 1987-1996. Epidemiological Prevalence 23: 98-104.

Safety, Health and Welfare at Work (Ireland) Act. 2005. http://www.oireachtas.ie. Accessed 12.16p.m. 11/01/2011.

Sanya, A.O. and Ogwumike O.O. 2005. Low back pain prevalence among industrial workers in the private sector in Oyo state, Nigeria. African Journal of Medicine and Medicinal Sciences 34:254-249.

Shrey, D.E. and Hursh N.C. 1999. Workplace disability management: International trends and perspectives.Journal of Occupational Rehabilitation 9(1): 45.

Svensson, H., Andersson G.J. and Wilheson V. 1998. A retrospective study of low back pain in 36 to 64 year old 
women, frequency of occurrence and impact on medical services. Spine 13: 548-552.

Van Tulder M., Becker A., Bekkering T. et al. 2006. European guidelines for the management of acute nonspecific low back pain in primary care. European Spine Journal 15(2):S169-S191.

Waddell G. 1998. The Back Pain Revolution. Edinburgh: Churchill Livingstone, 1998.

Waddell. G. and Burton A.K. 2000. Occupational Health Guidelines for the Management of Low Back Pain at WorkEvidence Review London: Faculty of Occupational
Medicine.

Williams, R.M. and Westmorland M. 2002. Perspectives on workplace disability management: A review of the literature. Work 19(1): 87-93.

Williams, R.M., Westmorland M.G. and Shammon H.S. 2007. Disability management practices in Ontario healthcare workplaces. Journal of Occupational Rehabilitation 17(1):153165.

\section{Appendix}

Management of Low Back Pain in WorkPlace Questionnaire (Cunningham, 2008 - adapted version)

Please fill in or tick your answers to many questions as possible.

1. Sex: Male $\square$ Female $\square$

\section{SECTION A}

2. Age (in years)

3. Occupation

4 Marital Status: Married

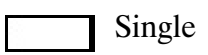

Widowed

Divorced

5. Length of time in current management post: Years Months

6. Length of time in current management Years Months

7. Number of staff currently being managed by you

\section{SECTION B}

Answer the following questions concerning your knowledge on low back pain by ticking and filling where appropriate.

8. Are there aspects of work which make it difficult for your staff to look after their backs Yes No

9. If yes, please specify

10. As a manager (head of department, assistant/deputy director, consultant, administrator) at $\mathrm{UCH}$, has any of your staff experienced low back pain which affected their work performance? Yes $\square$ No

11. If yes, please indicate how many times (approx) in the last year?

12. As a manager in $\mathrm{UCH}$, has any of your staff taken time off work as a result of low back pain? Yes

13. The responsibility for ensuring that staff members complete manual handling training lies with: No Please tick the appropriate box

Physiotherapy Department Personnel Department

Occupational Health Department 
Staff members

Don't know

Others please specify

14. In your experience at $\mathrm{UCH}$, has any of your staff members sustained a low back injury whilst at work?

Yes



15. If yes, please describe how the injury/injuries occurred(e.g. lifting a patient)

16. What immediate steps should you take in the case of a staff member sustaining a low back injury whilst at work?

If you don't know please tick

17. What immediate steps should you take in the case of a staff member sustaining a low back injury whilst at work?

If you don't know please tick

18. In the case of a staff member taking sick leave because of low back pain, with whom would you communicate?

Please tick the appropriate box(es)

Physiotherapist

Occupational therapist

Staff member

Personnel department

Don't know

Others please specify

\section{SECTION C}

Below are the attitude statements regarding low back pain in the work place. Please answer all statements and indicate whether you agree or disagree with each statement by circling the appropriate number on the scale ranging from $1=$ completely disagree to $5=$ completely agree.

\begin{tabular}{|c|c|c|c|c|c|}
\hline \multirow[b]{2}{*}{ 19. Most people recover from low back pain } & \multicolumn{2}{|c|}{ Disagree } & \multirow[b]{2}{*}{3} & \multicolumn{2}{|c|}{ Agree } \\
\hline & 1 & 2 & & 4 & 5 \\
\hline 20. Low back pain is common and often recurrent & 1 & 2 & 3 & 4 & 5 \\
\hline 21. Low back pain is common but is rarely due to any serious disease & 1 & 2 & 3 & 4 & 5 \\
\hline $\begin{array}{l}\text { 22. A small proportion of people with low back pain have severe pathology and are unlikely } \\
\text { to make a good recovery }\end{array}$ & 1 & 2 & 3 & 4 & 5 \\
\hline 23. Staff with low back pain should be pain free prior to returning to returning to work & 1 & 2 & 3 & 4 & 5 \\
\hline $\begin{array}{l}\text { 24. Offering lighter or modified duties to a staff member with low back pain is difficult in } \\
\text { my department }\end{array}$ & 1 & 2 & 3 & 4 & 5 \\
\hline 25. Staff members with low back pain should stay off work until they can return to full duty & 1 & 2 & 3 & 4 & 5 \\
\hline
\end{tabular}




\begin{tabular}{|c|c|c|c|c|c|}
\hline $\begin{array}{l}\text { 26. It is best for a manager not to make direct contact with the staff member whilst they are } \\
\text { on sick leave with low back pain }\end{array}$ & 1 & 2 & 3 & 4 & 5 \\
\hline $\begin{array}{l}\text { 27. To facilitate ongoing work/return to work, staff members should be allowed some time } \\
\text { for low back treatment during the working day }\end{array}$ & 1 & 2 & 3 & 4 & 5 \\
\hline 28. Some staff members use low back pain as an excuse to avoid certain work activities & 1 & 2 & 3 & 4 & 5 \\
\hline $\begin{array}{l}\text { 29. Some staff members display a negative attitude towards a work colleague with low back } \\
\text { pain }\end{array}$ & 1 & 2 & 3 & 4 & 5 \\
\hline $\begin{array}{l}\text { 30. Having a staff member with low back pain can make work more difficult for other staff } \\
\text { members }\end{array}$ & 1 & 2 & 3 & 4 & 5 \\
\hline $\begin{array}{l}\text { 31. Offering part time work/flexible hours to a staff member with low back pain is difficult in } \\
\text { my department }\end{array}$ & 1 & 2 & 3 & 4 & 5 \\
\hline $\begin{array}{l}\text { 32. It is difficult to know what level of work to expect from a staff member with low back } \\
\text { pain }\end{array}$ & 1 & 2 & 3 & 4 & 5 \\
\hline $\begin{array}{l}\text { 33. As a manager I rely on the staff member with low back pain to tell me what work tasks } \\
\text { are acceptable for them to perform }\end{array}$ & 1 & 2 & 3 & 4 & 5 \\
\hline $\begin{array}{l}\text { 34. As a manager I rely on the advice of health professionals to tell me what work tasks are } \\
\text { acceptable for a staff member with low back pain }\end{array}$ & 1 & 2 & 3 & 4 & 5 \\
\hline $\begin{array}{l}\text { 35. The longer anyone is off work with low back pain the lower their chances of ever } \\
\text { returning to work }\end{array}$ & 1 & 2 & 3 & 4 & 5 \\
\hline 36. Bed rest should not be recommended as a treatment for low back pain & 1 & 2 & 3 & 4 & 5 \\
\hline $\begin{array}{l}\text { 37. Lumbar belts or supports are beneficial in reducing work-related low back pain and } \\
\text { work loss }\end{array}$ & 1 & 2 & 3 & 4 & 5 \\
\hline $\begin{array}{l}\text { 38. In the case of most acute episode of back pain the worker should try to remain as active } \\
\text { as possible and to continue normal daily activities }\end{array}$ & 1 & 2 & 3 & 4 & 5 \\
\hline
\end{tabular}

SECTION D

39. Did you encounter any difficulty/problems in managing the staff members with low back pain?

40. If yees, please describe

41.What are the factors that might hinder return to work of staff members with low back pain?

42. In what ways could UCH offer better support to managers in relation to managing the staff members with low back pain?

Thank you for taking the time to complete this questionnaire. 